\title{
Education
}

\section{Effect of a brief emergency medicine education course on emergency department work intensity of family physicians}

\author{
Samuel Vaillancourt, MD, MPH*; Susan E. Schultz, MA, MSc ${ }^{\dagger}$; Chad Leaver, MSc ${ }^{\dagger}$; \\ Thérèse A. Stukel, $\mathrm{PhD}^{\dagger \ddagger \xi}$; Michael J. Schull, MD, MSc ${ }^{* \dagger \xi}$
}

\section{ABSTRACT}

Background: Recently, many Canadian emergency departments (EDs) have struggled with physician staffing shortages. In 2006, the Ontario Ministry of Health and Long-Term Care funded a brief "emergency medicine primer" (EMP) course for family physicians to upgrade or refresh skills, with the goal of increasing their ED work intensity. We sought to determine the effect of the EMP on the ED work intensity of family physicians.

Methods: A retrospective longitudinal study was conducted of the ED work of 239 family physicians in the 2 years before and after a minimum of 6 months and up to 2 years from completing an EMP course in 2006 to 2008 compared to nonEMP physicians. ED work intensity was defined as the number of ED shifts per month and the number of ED patients seen per month. We conducted two analyses: a before and after comparison of all EMP physicians and a matched cohort analysis matching each EMP physician to four non-EMP physicians on sex, year of medical school graduation, rurality, and pre-EMP ED work intensity.

Results: Postcourse, EMP physicians worked 0.5 more ED shifts per month ( $13 \%$ increase, $p=0.027)$. Compared to their matched controls, EMP physicians worked 0.7 more shifts per month (13\% increase, $p=0.0032)$ and saw 15 more patients per month $(17 \%$ increase, $p=0.0008)$ compared to matched non-EMP physicians. The greatest increases were among EMP physicians who were younger, were urban, had previous ED experience, or worked in a high-volume ED. The effect of the EMP course was negligible for physicians with no previous ED experience or working in rural areas.

Conclusion: The EMP course is associated with modest increases in ED work intensity among some family physicians, in particular younger physicians in urban areas. No increase was seen among physicians without previous ED experience or working in rural areas.

\section{RÉSUMÉ}

Contexte: Dernièrement, de nombreux services d'urgence (SU) au Canada ont eu à faire face à des pénuries de dotation en personnel médical. En 2006, le ministère de la Santé et des Soins de longue durée de l'Ontario a financé un cours " d'introduction à la médecine d'urgence " (IMU) à l'intention des médecins de famille pour actualiser leurs connaissances, dans l'optique d'accroître l'intensité du travail aux SU. L'étude visait donc à déterminer l'effet de ce cours sur I'intensité du travail des médecins de famille aux SU.

Méthode: II s'agit d'une étude rétrospective, longitudinale, sur le travail effectué aux SU par 239 médecins de famille au cours des 2 années précédant et suivant, sur une période d'au moins 6 mois et pouvant aller jusqu'à 2 ans, l'achèvement d'un cours d'IMU, de 2006 à 2008, comparativement à des médecins n'ayant pas suivi ce cours. L'intensité du travail aux SU était définie comme le nombre de périodes de travail par mois et le nombre de patients vus par mois. Nous avons effectué deux analyses: une comparaison avant/après de tous les médecins ayant suivi le cours d'IMU et une analyse de cohortes, appariée, dans laquelle chaque médecin ayant suivi le cours d'IMU était assorti à quatre médecins n'ayant pas suivi ce cours, quant au sexe, à l'année d'obtention du diplôme de médecine, au travail en milieu rural et à l'intensité du travail aux SU avant le cours d'IMU.

Résultats: Les médecins ayant suivi le cours ont travaillé 0.5 période de travail de plus par mois aux SU (augmentation de $13 \%, p=0.027)$. Comparativement à leurs témoins appariés, les médecins ayant suivi le cours ont travaillé 0.7 période de travail de plus par mois (augmentation de $13 \%, p=0.0032$ ) et ont vu 15 patients de plus par mois (augmentation de $17 \%$,

From the *Division of Emergency Medicine, Department of Medicine, University of Toronto, Toronto, ON; Institute for Clinical Evaluative Sciences, Toronto, ON; $\ddagger$ The Dartmouth Institute, Dartmouth College, Hanover, $\mathrm{NH}$; §Health Policy, Management and Evaluation, University of Toronto, Toronto, ON.

Correspondence to: Dr. Samuel Vaillancourt, G1 06, 2075 Bayview Avenue, Toronto, ON M4N 3M5; sam.vaillancourt@utoronto.ca.

This article has been peer reviewed. 
$p=0.0008$ ) que les médecins appariés n'ayant pas suivi le cours. Les plus fortes augmentations ont été enregistrées chez les jeunes médecins ayant suivi le cours, demeurant en milieu urbain, ayant une expérience antérieure aux SU ou ayant déjà travaillé dans un SU achalandé. L'effet du cours d'IMU était minime chez les médecins n'ayant pas d'expérience antérieure aux SU ou travaillant en milieu rural.

Conclusions: Le cours d'IMU s'est traduit par une légère augmentation de l'intensité du travail aux SU parmi certains médecins de famille, en particulier chez les jeunes médecins travaillant en milieu urbain; par contre, aucune augmentation n'a été relevée parmi les médecins n'ayant pas d'expérience antérieure aux SU ou travaillant en milieu rural.

Keywords: continuing medical education, emergency medicine, health policy, medically underserved area, physician practice patterns, physician shortage area, rural health services
Many communities across Canada face challenges in meeting the demand for physician services. Human resources shortages currently affect numerous emergency departments (EDs) across the country and have left some at risk of temporary or permanent closure, thereby threatening access to around-the-clock services for acute illnesses and injuries. ${ }^{1-4}$ Some family physicians (FPs) may be reducing the number of shifts they work in the ED or abandoning emergency medicine altogether due to concerns about the increasing complexity of the ED patient population.

Most small and some medium-sized EDs rely extensively, and often almost exclusively, on FPs without special training in emergency medicine, most of whom also practice in other settings. ${ }^{5}$ In contrast, FPs with an additional year of training in emergency medicine (CCFP-EMs) tend to practice full-time emergency medicine in medium- and high-volume centres, in a fashion similar to emergency medicine specialists (FRCPs). ${ }^{6}$ Through the 1990s, the proportion of FPs working in EDs steadily decreased ${ }^{7}$ despite an increasing number of ED visits over the same time period. ${ }^{8}$ These trends have contributed to supply/ demand mismatches for physician services in EDs, a major challenge faced across Canada. ${ }^{2}$ An illustrative example of this situation occurred in Ontario in 2006, when some communities, including Sault Ste. Marie (population 75,000 people), faced the prospect of temporary closure of their EDs due to staffing shortfalls. ${ }^{1,9}$ Several strategies and considerable resources involving both incentives and, on occasion, involuntary service have been implemented across Canada to address similar situations. ${ }^{3,10}$

In 2006, the Ontario Ministry of Health and LongTerm Care (MOHLTC), in conjunction with MedEmerg Healthcare Solutions Inc. and the Ontario College of Family Physicians (OCFP), developed a 2-day emergency medicine primer (EMP) course. The EMP was developed to address the shortage of physicians in the
ED by influencing FPs who were reluctant or less willing to work in EDs due to increasing patient complexity. The purpose of the course was to upgrade or refresh skills, with the goal that participants would increase (or begin) ED work. ${ }^{11}$

The EMP course provides 1630 -minute case-based didactic sessions and 445 -minute practical workshops over 2 days. Prior to the course, participants collectively select the 16 sessions from a list of 21 topics. The topics offered range from pediatric emergencies and electrocardiogram interpretation to toxicology and airway management and reflect the breadth of core emergency medicine material. To date, the curriculum has undergone revisions once or twice a year. Physicians do not pay to take the course.

The primary purpose of this study was to determine the effect of the EMP course on the ED work intensity of family physicians and, by extension, the effectiveness of the EMP course on achieving its goal. For the purpose of this study, we defined work intensity as 1) the number of patients seen per month by a physician and 2) the number of shifts worked per month.

\section{METHODS}

\section{Data sources}

Data for this study were obtained from several sources. The EMP registration form provided information about who attended each course. Physician registration numbers from the College of Physicians and Surgeons of Ontario (CPSO) were obtained from the CPSO website. After removing identifying information such as name and street address, the CPSO numbers were encrypted, and these encrypted numbers were linked to other administrative data. The Ontario Health Insurance Plan (OHIP) database of physician billings was used to calculate each physician's ED work before and after the EMP and to identify the hospital(s) where 
they worked. The OHIP Corporate Provider Database and Institute for Clinical Evaluative Sciences (ICES) Physician Database provided information about each physician's year of graduation, age, and sex. ED volume data were derived from the National Ambulatory Care System (NACRS) database of ED visits.

\section{Study design and time frame}

We conducted a retrospective longitudinal study of FPs who completed one of the 13 EMP courses given between July 2006 and August 2008. The overall study period was from July 2004 (24 months before the first EMP course) to February 28, 2009 (6 months after the last EMP course studied). This allowed a minimum of 6 months of follow-up for all EMP participants.

\section{Outcome measure}

Our primary outcome measure was the mean change in physician ED work intensity before and after taking the EMP course. ED work intensity was defined as 1) the number of shifts worked in the ED per month and 2) the number of ED patients seen per month. An ED shift was defined as any day on which a physician saw three or more patients in the ED.

\section{Data analysis}

We conducted two analyses of the effect of the EMP course. First, we carried out before/after analyses of EMP physician ED work intensity; separate models were created for physicians with and without previous ED work experience (defined as greater than one shift worked in the 2 years preceding the EMP). For EMP physicians, the previous or pre-EMP period was the 24 months before their EMP course or the period from the date they became eligible to bill OHIP to the date of their EMP course, whichever was longer. The follow-up period was the period from their EMP course to February 28, 2009, up to a maximum of 24 months.

The second analysis was a matched cohort design in which we matched each EMP physician who had previous ED experience with four physicians who had done at least one shift in an Ontario ED during the study period but did not take the EMP course to strengthen our ability to determine whether any pre/ post differences in ED work intensity seen among the EMP physicians were attributable to the course itself.
Physicians were matched on sex, decade of graduation from medical school, rurality of their practice address, and ED work intensity prior to the EMP. Physicians with no previous ED experience were excluded from this analysis because cases and controls needed to have similar propensities to ever work in an ED and controls with no ED experience might be unwilling or unable to ever work in an ED.

To provide context to our primary results, we also conducted a secondary analysis to determine the secular trend in ED work intensity for all FPs working in EDs over the full 4-year study period. We included all FPs who did not take an EMP course but worked at least one shift in an Ontario ED in the 2 years preceding the first course. Similar to the first EMP analysis, we conducted a pre/post analysis comparing the ED work intensity of these physicians in the 24 months prior to the first EMP course to their ED work intensity following the course. All analyses were limited to active FPs with or without CCFP-EM certification. Although CCFP-EM-certified physicians are known to be more active in ED practice, they were included as we hypothesized that they would face similar choices with regard to practice patterns as non-CCFP-EM-certified FPs given their general practice licence. Emergency medicine specialists (FRCPs) were excluded because most already have an exclusive or majority clinical focus in the ED, and this group was not a target of the EMP course. The Research Ethics Board of Sunnybrook Health Sciences Centre approved the study.

\section{RESULTS}

Overall, 2,989 FPs worked at least one shift in an Ontario ED during the study period. Of these, 239 took an EMP course. Table 1 shows that EMP physicians were similar to the overall sample with respect to gender and practice distribution. However, EMP physicians were less likely to have an additional year of training in emergency medicine (6.7\% with CCFP-EM certification v. $19.2 \%$ overall), tended to be younger (age under 35 years, $23.0 \%$ v. $16.4 \%$; age $45+$ years, $38.0 \%$ v. $47.2 \%$ ) and were more likely to be recent medical school graduates (graduated in 2000+, 28.0\% v. $19.1 \%$ ). Fewer EMP physicians had worked in the ED in the 2 years preceding their EMP course $(62.7 \%$ v. $80.0 \%)$ and, if they had, were less likely to have worked at high intensity $(20.9 \%$ v. $37.1 \%)$ or to have worked in a highvolume centre $(19.2 \%$ v. $30.1 \%)$. 


\begin{tabular}{|c|c|c|}
\hline & FPs who attended one of 13 EMPs & All FPs with ED activity* \\
\hline & $n(\%)$ & $n(\%)$ \\
\hline Overall & $239(100)$ & $2,989(100)$ \\
\hline \multicolumn{3}{|l|}{ Training } \\
\hline General licence or CCFP certification & $223(93.3)$ & $2414(80.8)$ \\
\hline CCFP-EM certification & $16(6.7)$ & $575(19.2)$ \\
\hline \multicolumn{3}{|l|}{ Sex } \\
\hline Women & 81 (33.9) & 875 (29.3) \\
\hline Men & $158(66.1)$ & $2,114(70.7)$ \\
\hline \multicolumn{3}{|l|}{ Age (yr) } \\
\hline$<35$ & $55(23.0)$ & $489(16.4)$ \\
\hline $35-39$ & $45(18.8)$ & $571(19.1)$ \\
\hline $40-44$ & $48(20.1)$ & $508(17.0)$ \\
\hline $45-54$ & $57(23.8)$ & $868(29.0)$ \\
\hline $55+$ & $34(14.2)$ & $553(18.5)$ \\
\hline \multicolumn{3}{|l|}{ Year of graduation (MD) } \\
\hline $2000+$ & $67(28.0)$ & $572(19.1)$ \\
\hline 1990-1999 & $81(33.9)$ & $1,018(34.1)$ \\
\hline 1980-1989 & $57(23.8)$ & $776(26.0)$ \\
\hline$<1980$ & $34(14.2)$ & $623(20.8$ \\
\hline \multicolumn{3}{|l|}{ RIO group } \\
\hline Major urban & $129(54.0)$ & $1,555(52.0$ \\
\hline Urban & $53(22.2)$ & 835 (27.9) \\
\hline Rural & $57(23.8)$ & $599(20.0)$ \\
\hline \multicolumn{3}{|l|}{ ED intensity prior to the first EMP (July 16,2006 ) } \\
\hline Low (> 0-1.8 shifts/mo) & $47(19.7)$ & $585(19.6)$ \\
\hline Medium (> 1.8-5.6 shifts/mo) & $48(20.1)$ & 654 (21.9) \\
\hline High (> 5.6 shifts/mo) & $50(20.9)$ & $1,110(37.1)$ \\
\hline No shifts & 94 (39.3) & $640(21.4)$ \\
\hline $\begin{array}{l}\text { Hospital type (by ED volume) for physicians with ED } \\
\text { work in the } 2 \text { yr preceding the EMP }\end{array}$ & $150(62.7)$ & $2391(80.0)$ \\
\hline Low volume (<15,000 visits/yr) & $45(18.8)$ & 417 (14.0) \\
\hline Medium volume $(15,000-40,000$ visits/yr $)$ & $59(24.7)$ & $1,073(35.9)$ \\
\hline High volume (> 40,000 visits/yr) & $46(19.2)$ & $901(30.1)$ \\
\hline
\end{tabular}

Among EMP physicians, we found a modest but significant overall increase in average ED work intensity post-EMP; however, the effect of the course differed substantially across subgroups. Among physicians with previous ED experience (Table 2), the increase in both shifts and patients seen per month was greatest among younger physicians and recent medical school graduates $(<35$ years increased by 1.4 shifts per month; graduates from $2000+$ increased by 1.5 shifts per month) and those located in a major urban area, who increased their work intensity by 1.0 shift per month. The effect of the EMP was also greater among physicians with low or medium ED work intensity prior to the EMP (increases of 0.7 and 1.2 shifts per month, respectively) and those who worked in high-volume EDs (average increase 1.2 shifts per month). Interestingly, FPs located in rural areas showed essentially no change in their ED practice after the EMP.

Table 3 provides results among physicians with no previous ED experience. Some physicians with no ED experience prior to taking the EMP began to work in EDs after the course; however, the average number of shifts and number of patients seen per month were substantially lower than pre or post rates for physicians with ED experience. Nonetheless, higher ED work intensity post-EMP was seen among younger physicians 


\begin{tabular}{|c|c|c|c|c|}
\hline & \multirow[b]{2}{*}{$n$} & \multicolumn{3}{|c|}{ Mean shifts/mo } \\
\hline & & Pre-EMP & Post-EMP & $\%$ change \\
\hline Overall & 145 & 4.3 & 4.8 & $12.9(p=.027)$ \\
\hline \multicolumn{5}{|l|}{ Age (yr) } \\
\hline$<35$ & 34 & 4.0 & 5.4 & 34.4 \\
\hline $35-39$ & 28 & 5.2 & 5.4 & 5.7 \\
\hline $40-44$ & 25 & 4.9 & 5.0 & 0.9 \\
\hline $45-54$ & 39 & 3.4 & 3.9 & 13.3 \\
\hline $55+$ & 19 & 4.3 & 4.6 & 7.9 \\
\hline \multicolumn{5}{|l|}{ Year of graduation (MD) } \\
\hline $2000+$ & 41 & 4.0 & 5.5 & 38.6 \\
\hline 1990-1999 & 47 & 5.0 & 5.1 & 2.2 \\
\hline 1980-1989 & 36 & 4.3 & 4.6 & 7.1 \\
\hline$<1980$ & 21 & 3.3 & 3.4 & 3.7 \\
\hline \multicolumn{5}{|l|}{ Rurality of practice } \\
\hline Major urban & 58 & 3.4 & 4.4 & 31.2 \\
\hline Urban & 35 & 4.2 & 4.7 & 12.6 \\
\hline Rural & 52 & 5.4 & 5.4 & -0.1 \\
\hline \multicolumn{5}{|l|}{ ED intensity prior to EMP } \\
\hline Low (> 0-1.8 shifts/mo) & 47 & 0.6 & 1.3 & 107.2 \\
\hline Medium (> 1.8-5.6 shifts/mo) & 48 & 3.8 & 4.6 & 20.7 \\
\hline High (> 5.6 shifts/mo) & 50 & 8.3 & 8.5 & 2.3 \\
\hline \multicolumn{5}{|l|}{ Hospital type (by ED volume) } \\
\hline Low volume & 45 & 4.0 & 4.2 & 5.0 \\
\hline Medium volume & 56 & 4.6 & 5.0 & 8.7 \\
\hline High volume & 44 & 4.3 & 5.5 & 27.9 \\
\hline \multicolumn{5}{|l|}{ EMP training year } \\
\hline 2006 & 25 & 3.9 & 4.0 & 2.3 \\
\hline 2007 & 46 & 3.8 & 4.4 & 16.4 \\
\hline 2008 & 74 & 4.8 & 5.6 & 16.0 \\
\hline
\end{tabular}

$(<35$ years worked additional 2.2 ED shifts/month on average) and recent medical school graduates (graduates 2000+ worked an additional 2.3 ED shifts/month on average).

In the matched cohort analysis, we found that physicians who took the EMP worked 0.65 more ED shifts per month $(p=0.0032)$ and saw 14.8 more ED patients per month $(p=0.0008)$ compared to matched controls who did not take the course. When these results were totaled, the 13 EMP courses were associated with 1,131 additional ED shifts being done annually and 25,752 additional ED patients being seen annually by the 145 EMP physicians with previous ED experience.

In our analysis of the secular trend in ED work intensity among the 2,341 FPs working in EDs who did not take an EMP course, we found a small but significant decrease in the average number of ED shifts worked per month from 6.4 to $6.1(p=0.000003)$ over the 4-year study period. The mean number of patients seen per month also decreased from 129 to 123 ( $p=$ $0.000003)$. Figure 1 illustrates that this reduction in ED work intensity over time was found across all subgroups of physicians with the exception of those under age 35, who increased their average ED work intensity from 4.5 to 6.1 shifts per month, representing an increase of 1.6 shifts per month. Totaled across all 2,341 non-EMP FPs, this secular trend represents an overall decrease of 8,428 ED shifts worked per year.

\section{DISCUSSION}

Our results indicate that FPs who take an EMP course increase their ED work intensity in the 2 years following the course. The matched cohort analysis 


\begin{tabular}{|c|c|c|}
\hline & $n$ & Mean shifts/mo post-EMP \\
\hline Overall & 94 & $0.7(p=.023)$ \\
\hline \multicolumn{3}{|l|}{ Age (yr) } \\
\hline$<35$ & 21 & 2.2 \\
\hline $35-39$ & 17 & 0.8 \\
\hline $40-44$ & 23 & 0.0 \\
\hline $45-54$ & 18 & 0.2 \\
\hline $55+$ & 15 & 0.0 \\
\hline \multicolumn{3}{|c|}{$\begin{array}{l}\text { Year of graduation } \\
\text { from MD }\end{array}$} \\
\hline $2000+$ & 26 & 2.3 \\
\hline 1990-1999 & 34 & 0.0 \\
\hline 1980-1989 & 21 & 0.2 \\
\hline$<1980$ & 13 & 0.0 \\
\hline \multicolumn{3}{|c|}{ EMP training year } \\
\hline 2006 & 7 & 0.8 \\
\hline 2007 & 46 & 0 \\
\hline 2008 & 41 & 1.4 \\
\hline
\end{tabular}

shows that the increase in work intensity is greater for physicians who take the EMP course than for those who do not. Overall, average increases of $13 \%$ in shifts per month and $17 \%$ in ED patients per month were seen among physicians with previous ED experience, with up to threefold larger increases seen among some physician subgroups. The largest increases in ED work intensity were seen in FPs who were young, recent graduates already working part time in the ED or working in high-volume centres. Smaller increases in average ED work intensity were seen among physicians without previous ED experience.

These results contrast with those of our secular trend analysis, which indicated a small reduction of ED work intensity over the study period for most FPs, with the exception of younger physicians. Although the absolute reduction was small, given the large number of physicians, it cumulatively amounted to over 8,000 fewer ED shifts worked per year in the last 2 years of our study compared to the first two. These results suggest that interventions intended to offset this trend such as the EMP course must either reach substantially more physicians or be better designed to address factors leading physicians to reduce their ED work intensity.

There is little known about why FPs leave ED practice or why many FPs never enter such practice. A study of American emergency physicians found relatively low levels of attrition from practice, but these were specialist emergency physicians as opposed to FPs working in EDs. ${ }^{2}$ A Canadian study showed that the proportion of FPs in Ontario engaged in "office-only" practices, which excluded ED work, increased substantially in the 1990s. ${ }^{8}$ An older and more complex ED patient population, evolving expectations for the provision of sophisticated ED treatment, and worsening problems of ED overcrowding 7 may all be barriers to ED work for family doctors. In addition, Ontario's recent primary care

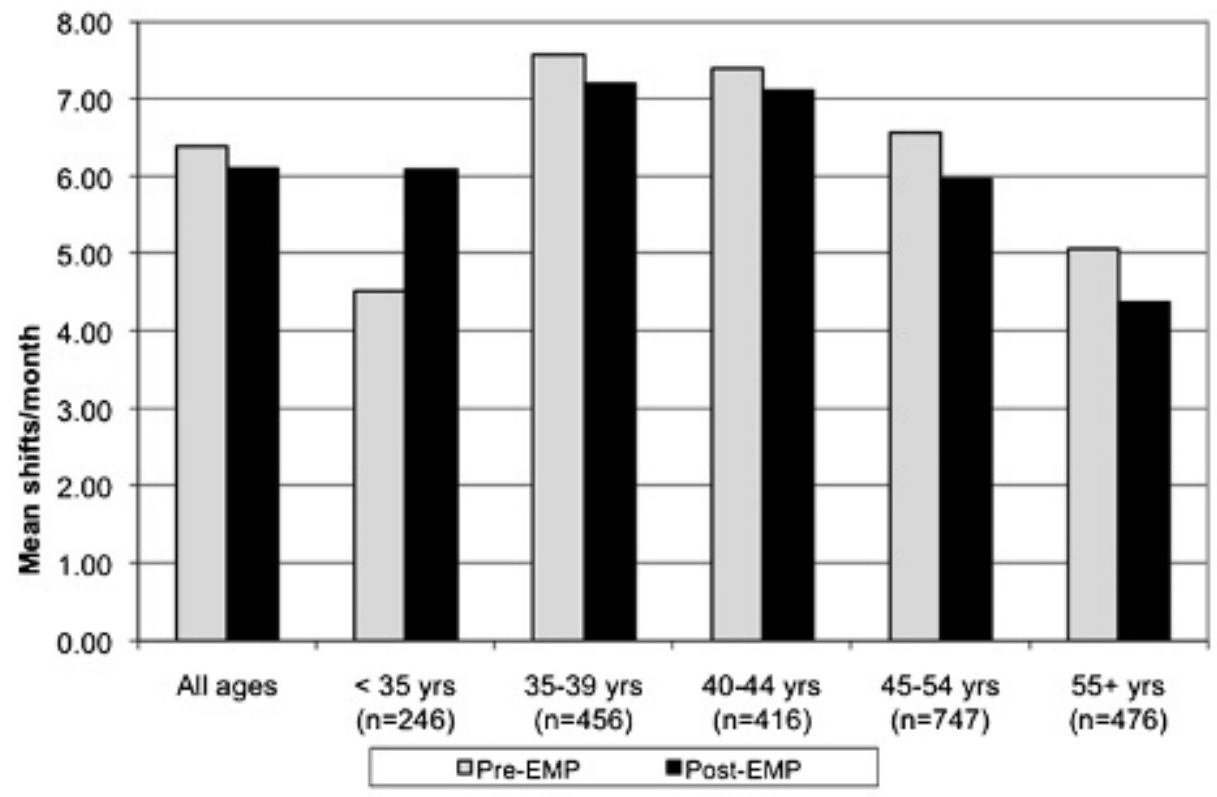

Figure 1. Change in average number of emergency department shifts per month before and after the first emergency medicine primer (EMP) course of 2,750 family physicians who did not take an EMP course, by age group. 
reform initiatives may act as a disincentive for FPs to work in the ED by making office-based primary care more attractive and requiring physicians to provide after-hours care in their own practices. ${ }^{13}$

Continuing medical education (CME) programs designed to improve FP knowledge and comfort in dealing with a more complex ED patient population are one potential way to improve this situation. The impact of CME on physician's uptake of new medical knowledge and practices has been the subject of numerous studies. Most have focused on interventions to modify physicians' management of a chronic condition, the provision of preventive services, or prescribing patterns. There is evidence that interactive small-group sessions, similar to the structure of the EMP course, can help in achieving these goals..$^{14,15}$

The EMP course integrates some well-validated techniques but seeks a more complex outcome (increased work intensity in EDs) than traditional CME programs. The EMP program touches on two important health policy and health care questions: 1) how to encourage physicians to work in underserved areas and 2) how to influence physician behaviour, regardless of practice location. As in many Western countries, the challenge of health human resources recruitment and retention in smaller communities has been well documented in health care systems across Canada. ${ }^{2}$ Some programs have had positive results, albeit over decades, by focusing on undergraduate medical education, including admission policies, curriculum, and clerkship electives. ${ }^{16,17}$ Other programs designed to create financial incentives have yielded more immediate results. ${ }^{18}$

Our study could not isolate the effect of the EMP course from selection bias arising from those who took the course. Physicians who choose to take an EMP course likely do so with the intention of increasing their ED work, regardless of the nature of the course itself. This may be particularly relevant to new graduates with no previous ED experience. Similarly, some physicians working in the ED may have seen the EMP as an opportunity for low-cost CME and registered with no intention of changing their ED work intensity. This would reduce the observed effect of the EMP.

Our analysis relies on OHIP billing data, which may not fully reflect ED work due to incomplete shadow billing. We also were not able to capture ED shifts where physicians were "on call" (i.e., available to be called in to an ED) but where no patient encounters occurred and no billings were generated. This issue is likely most relevant to small rural EDs with night shift coverage. In addition, consensus definitions of an ED shift and a physician with ED activity were used for the purposes of this study and may not reflect the diversity of practice among Ontario's FPs.

This study was limited to assessing the EMP's success in achieving its primary objective of increasing the work intensity of FPs in the ED. We were unable to assess the effect of the EMP on physician clinical competence and confidence. These effects currently lack standardized, quantifiable measurements and cannot be meaningfully extracted from administrative data.

\section{CONCLUSION}

The EMP course is associated with modest increases in ED work intensity among some FPs, in particular younger physicians in urban areas. No increase was seen among physicians without previous ED experience or working in rural areas. Focusing the EMP on younger doctors, more recent graduates, and those with some ED experience but not already working many ED shifts per month might increase the impact of the course. Alternatively, understanding more clearly why some physicians who took the course did not substantially increase their ED work intensity or ensuring that registrants clearly express an intention to increase ED work intensity might increase the impact of courses such as the EMP. Short, interactive, educational interventions may deserve further consideration as policy instruments to address physician shortages in certain geographic and clinical areas of practice. Nonetheless, other interventions, models of care, or incentives are likely needed to ensure sufficient ED medical staffing given that the overall trend among most FPs is toward a reduction in ED work intensity.

Acknowledgements: We wish to thank the OCFP for the provision of the EMP registration database, without which this evaluation of the EMP would not have been possible.

Competing interests: Funding for this project came from the Canadian Health Services Research Foundation through a grant for the Canadian Institutes of Health Research Chair in Health Services and Policy Research. This study was supported by the ICES, which is funded by an annual grant from the Ontario MOHLTC. The opinions, results, and conclusions reported in this article are those of the authors and are independent from the funding sources. No endorsement by ICES or the Ontario MOHLTC is intended or should be inferred. 


\section{REFERENCES}

1. Urquhart I. MDs refuse emergency work. The Toronto Star. 2006 Sept 25. Available at: http://www.thestar.com/news/ ontario/article/96395--mds-refuse-emergency-work (accessed September 26, 2012).

2. Romanow RJ, editor. Building on values: the future of bealth care in Canada. Saskatoon (SK): Commission on the Future of Health Care in Canada; 2002.

3. Pengelley H. Quebec's decision to draft MDs to work in ERs creates storm. CMA7 2002;167:5.

4. Pong RW. Strategies to overcome physician shortages in northern Ontario: a study of policy implementation over 35 years. Hum Resources Health 2008;6:24, doi:10.1186/14784491-6-24.

5. Pong RW, Pitblado JR. Geographic distribution of physicians in Canada: beyond bow many and where. Ottawa: Canadian Institute for Health Information; 2005.

6. Chan BT. Do family physicians with emergency medicine certification actually practise family medicine? CMAJ 2002; 167:869-70.

7. Ontario Hospital Association, Ontario Medical Association, Ontario Ministry of Health and Long-Term Care. Improving access to emergency care: addressing system issues. Toronto; 2006.

8. Chan BT, Schull MJ, Schultz SE. Emergency department services in Ontario: atlas report. Toronto: Institute for Clinical Evaluative Sciences; 2001.

9. Statistics Canada. Population and dwelling counts, Sault Ste. Marie, Ontario (city). Available at: http://www12.statcan.ca/ census-recensement/2006/dp-pd/prof/92-591/details/page. $\mathrm{cfm}$ ?Lang $=\mathrm{E} \& \mathrm{Geo} 1=\mathrm{CSD} \& \mathrm{Code} 1=3557061 \& \mathrm{Geo} 2=\mathrm{PR}$ $\&$ Code $2=35 \&$ Data $=$ Count $\&$ SearchText $=$ Sault $\&$ Search Type $=$ Begins $\&$ SearchPR $=01 \& B 1=$ All $\&$ Custom $=($ accessed November 19, 2009).
10. Pong RW, Russell N. A review and synthesis of strategies and policy recommendations on the rural bealth workforce. Sudbury (ON): Centre for Rural and Northern Health Research; 2003.

11. Ontario College of Family Physicians. Emergency medicine primer for family physicians. Available at: http://www.ocfp.on.ca/ English/OCFP/EMPrimer07/ (accessed November 19, 2009).

12. Ginde AA, Sullivan AF, Camargo CA. Attrition from emergency medicine clinical practice in the United States. Ann Emerg Med 2010;56:166-71, doi:10.1016/j.annemergmed. 2009.11.002.

13. Glazier RH, Klein-Geltink J, Kopp A, et al. Capitation and enhanced fee-for-service models for primary care reform: a population based evaluation. CMA7 2009;180:E72-81, doi: 10.1503/cmaj.081316.

14. Oxman AD, Thomson MA, Davis DA, et al. No magic bullets: a systematic review of 102 trials of interventions to improve professional practice. CMA7 1995;153:142331.

15. Thomson O'Brien MA, Freemantle N, Oxman AD, et al. Continuing education meetings and workshops: effects on professional practice and health care outcomes. Cochrane Database Syst Rev 2001;(2):CD003030.

16. Rabinowitz HK, Diamond JJ, Markham FW, et al. A program to increase the number of family physicians in rural and underserved areas: impact after 22 years. $7 A M A 1999$; 281:255-60, doi:10.1001/jama.281.3.255.

17. Rabinowitz HK, Diamond JJ, Markham FW, et al. Critical factors for designing programs to increase the supply and retention of rural primary care physicians. FAMA 2001;286: 1041-8, doi:10.1001/jama.286.9.1041.

18. Sempowski IP. Effectiveness of financial incentives in exchange for rural and underserviced area return-of-service commitments: systematic review of the literature. Can 7 Rural Med 2004;9:82-8. 